\title{
Diagnostic accuracy of basal TSH determinations based on the intravenous TRH stimulation test: An evaluation of 2570 tests and comparison with the literature Helga Moncayo ${ }^{1,3}$, Otto Dapunt ${ }^{1,3}$ and Roy Moncayo*1,2,3
}

Address: ${ }^{1}$ Department of Obstetrics and Gynecology, University of Innsbruck, Anichstrasse 35, A-6020 Innsbruck, Austria, ${ }^{2}$ Department of Nuclear Medicine, Medical University Innsbruck, Austria and ${ }^{3}$ WOMED, Karl-Kapferer-Strasse 5, 6020 Innsbruck, Austria

Email: Helga Moncayo - anmeldung@womed.at; Otto Dapunt - anmeldung@womed.at; Roy Moncayo* - anmeldung@womed.at

* Corresponding author

Published: 2 August 2007

BMC Endocrine Disorders 2007, 7:5 doi:10.1186/1472-6823-7-5

This article is available from: http://www.biomedcentral.com/1472-6823/7/5

(C) 2007 Moncayo et al; licensee BioMed Central Ltd.

This is an Open Access article distributed under the terms of the Creative Commons Attribution License (http://creativecommons.org/licenses/by/2.0), which permits unrestricted use, distribution, and reproduction in any medium, provided the original work is properly cited.
Received: 3 August 2006

Accepted: 2 August 2007

\begin{abstract}
Background: Basal TSH levels reflect the metabolic status of thyroid function, however the definition and interpretation of the basal levels of TSH is a matter of controversial debate. The aim of this study was to evaluate basal TSH levels in relation to the physiological response to i.v. TRH stimulation.
\end{abstract}

Methods: A series of 2570 women attending a specialized endocrine unit were evaluated. A standardized i.v. TRH stimulation test was carried out by applying $200 \mu \mathrm{g}$ of TRH. TSH levels were measured both in the basal and the 30 minute blood sample. The normal response to TRH stimulation had been previously determined to be an absolute value lying between 2.5 and $20 \mathrm{mlU} /$ I. Both TSH values were analyzed by cross tabulation. In addition the results were compared to reference values taken from the literature.

Results: Basal TSH values were within the normal range $(0.3$ to $3.5 \mathrm{mIU} / \mathrm{l})$ in $91,5 \%$ of cases, diminished in $3,8 \%$ and elevated in $4.7 \%$. Based on the response to $\mathrm{TRH}, 82.4 \%$ were considered euthyroid, 3.3\% were latent hyperthyroid, and $14.3 \%$ were latent hypothyroid. Combining the data on basal and stimulated TSH levels, latent hypothyroidism was found in the following proportions for different TSH levels: 5.4\% for TSH $<2.0 \mathrm{mIU} / \mathrm{l}, 30.2 \%$ for TSH between 2.0 and $3.0 \mathrm{mIU} / \mathrm{l}, 65,5 \%$ for TSH between 3.0 and $3.50 \mathrm{mIU} / \mathrm{I}, 87.5 \%$ for TSH between 3.5 and $4.0 \mathrm{mIU} / \mathrm{l}$, and $88.2 \%$ for TSH between 4 and $5 \mathrm{mIU} / \mathrm{l}$. The use of an upper normal range for TSH of $2.5 \mathrm{mIU} / \mathrm{l}$, as recommended in the literature, misclassified $7.7 \%$ of euthyroid cases.

Conclusion: Our analysis strategy allows us to delineate the predictive value of basal TSH levels in relation to latent hypothyroidism. A grey area can be identified for values between 3.0 and 3.5 $\mathrm{mIU} / \mathrm{l}$.

\section{Background}

Elevated levels of TSH are the hallmark of decreased thyroid function. In order to correctly identify these patients it is imperative to have a clear definition of the upper ref- erence range for basal TSH. Patients whose TSH lies in the upper reference range might appear to have minimal thyroid deficiency. Although this might appear to be an easy task, the definition of the upper reference range for TSH 
has been matter of controversial debate [1-5]. Reported reference values for the upper range of basal TSH vary between 2.12 and $5.95 \mathrm{mIU} / \mathrm{l}$ [6-21] (Table 1). In the majority of studies, the reference range for TSH has been defined by statistical analysis (95\% confidence interval) of log transformed data. An alternative approach is to rely on the physiological response of TSH to TRH stimulation [22] taking the absolute TSH values 30 minutes after TRH stimulation as the classification criteria $[17,23,24]$.

Within the setting of a fertility unit, the exclusion or identification of causes of infertility requires a broad diagnostic approach. In a recent review by Poppe, Velkeniers, and Glinoer, special emphasis was put on the evaluation of thyroid function [25]. Referring to thyroid function tests, the authors commented the apparent discrepancy between basal and TRH-stimulated TSH levels used to detect subclinical hypothyroidism (Table 1 in [25]). The aim of this retrospective study was to describe in more detail the relation of basal TSH levels to the TRH-stimulated levels and their validity for the detection of latent hypothyroidism. Data analysis was also carried out in comparison with criteria reported in the literature.

\section{Methods}

The laboratory methods used have been described elsewhere [17]. A total of 2570 women attending the outpatient unit for Reproductive Endocrinology at the University of Innsbruck were studied (mean age 31 years, min. 21 years, max. 69 years). All patients were ambulatory and did not present any severe disease nor were taking any medication that could interfere with thyroid function tests. Ninety percent of patients were consulting the service due to irregularities of the menstrual cycle, or infertility. Ten percent of cases corresponded to menopausal women. Patients with known thyroid disease were excluded. Informed consent was obtained according to the Declaration of Helsinki. The study was approved by the institutional Ethics Committee. The TRH test was carried out by i.v. application of $200 \mu \mathrm{g}$ of TRH. Both a basal and a 30 minute blood sample were obtained. In the first sample, both thyroid hormones (fT3 and fT4) and TSH were determined; in the second one only TSH was measured. Antibody levels were not determined. The reference values for basal TSH had been previously evaluated based on ROC analysis and lied between 0.3 to $3.5 \mathrm{mIU} / \mathrm{l}$ [17]. These reference values will be called I-TSH in further comparisons. An absolute TSH increase between 2.5 and 20 $\mathrm{mIU} / \mathrm{l}$ following TRH stimulation was defined as normal [17]. The definition of these levels comes from a detailed internal evaluation of both clinical and laboratory data of 2870 patients being investigated at the out-patient unit of the Department of Nuclear Medicine, University of Innsbruck in 1993. The data from these patients was analyzed in relation to age, gender, iodine excretion, scintigraphy, sonography, and thyroid function tests (data not shown). These criteria were also used in a later analysis of 12.838 subjects done 2003 [17]. Altogether a total of 15708 subjects provide the foundation for the present analysis.

The reference ranges from the literature were taken from Zöphel [19] and Baloch [26]. These will be referred to as Z-TSH and B-TSH. A normal measured Z-TSH lies between 0.3 to $3.35 \mathrm{mIU} / \mathrm{l}$, while a normal B-TSH has been proposed to be between 0.4 to $2.5 \mathrm{mIU} / \mathrm{l}$.

Table I: Comparison of TSH reference levels from the literature

\begin{tabular}{lcccc}
\hline Author & Year & $\mathbf{n}$ & Population Age in years & TSH levels \\
\hline De Rosa [6] & 1996 & 259 & $12-82$ & $0.3-3.32$ \\
Taimela [7] & 1997 & 262 & $23-69$ & $0.6-4.3$ \\
Bjoro [8] & 2000 & $19327 \mathrm{f}$ & $0.49-5.70 \mathrm{f}$ \\
& & $9754 \mathrm{~m}$ & $20-80$ & $0.56-4.60 \mathrm{~m}$ \\
Steinmetz [9] & 2000 & 1348 & $45-70$ & $0.43-3.71$ \\
Hollowell [10] & 2002 & 13344 & $12-80$ & $0,45-4,12$ \\
Hubl [II] & 2002 & 1030 & $18-90$ & $0.19-4.25$ \\
Hübner [12] & 2002 & 43 & $15-18$ (study subgroup) & $0.56-4.53$ \\
Gonzalez-Sagrado [13] & 2004 & 304 & $12-94$ & $0.51-5.95$ \\
Jensen [14] & 2004 & 1512 & $17-66$ & $0.58-4.07$ \\
D'Herbomez [15] & 2005 & 710 & $18-65$ & $0.35-3.48$ \\
Kratzsch [16] & 2005 & 870 & $18-68$ & $0.3-3.63$ \\
Moncayo [17] & 2005 & 14981 & $20-89$ & $0.3-3.5$ \\
Völzke [18] & 2005 & 1488 & $20-79$ & $0.25-2.12$ \\
Zöphel [19] & 2005 & 1442 & Unkown & $0.3-3.35$ \\
Dhatt [20] & 2006 & 959 & $16-75$ & $0.3-4.32$ \\
O'Leary [2I] & 2006 & 2026 & $29-70$ & $0.4-4.0$ \\
Total number of observations & & 69659 & & \\
\hline
\end{tabular}




\section{Data Analysis}

The laboratory results were classified according to the criteria presented by Dayan [27]. Statistical analysis (one way ANOVA) was done with SPSS version 12. A p-value less than 0.01 was called significant.

\section{Results}

Analysis of fT3 and fT4 and of basal TSH levels

Stratification of data according to age groups did not reveal any age-dependency of thyroid function parameters (fT3, fT4, or TSH; one way ANOVA, data not shown). The classification of cases according to the levels of the free thyroid hormone showed $86,65 \%$ of cases to lie within the normal range, $2.3 \%$ lied above and $11.05 \%$ below. The proportion of patients having a normal basal TSH according to the 3 evaluation criteria was: $91.52 \%$ for ITSH, 90.66 for Z-TSH and 83.77 for B-TSH, respectively. The lower number of euthyroid cases using the B-TSH criteria was accompanied by a $7.76 \%$ increase in the proportion of cases classified as having elevated TSH levels (Table 2).

A cross tabulation analysis of both free thyroid hormones and basal TSH (Table 3) showed that the normal ranges for the I-TSH and Z-TSH criteria corresponded to 80 and $79,34 \%$ of the subjects who also had normal thyroid hormone (TH) levels. In contrast to this, the proposed B-TSH criteria recognized only $73,46 \%$ of cases with normal $\mathrm{TH}$ levels as having a normal TSH. Again, the proposed B-TSH criteria classified twice as many patients as the I-TSH and Z-TSH criteria as hypothyroid/latent hypothyroid.

\section{Analysis of the stimulated TSH levels}

When the normal TSH response to TRH was compared to basal TSH levels, $80.81 \%$ of cases were called normal according to I-TSH, $80.54 \%$ for Z-TSH and $76.79 \%$ for BTSH. Comparing both TSH results, i.e. basal and stimulated, an increasingly significant number of latent hypothyroid patients could be found when basal TSH was between 3 and 4. Latent hypothyroidism, defined as an elevated TSH after TRH, was found in the following proportions for different TSH levels: $5.4 \%$ for TSH $<2.0 \mathrm{mIU} /$ 1, 30.2\% for TSH between 2.0 and $3.0 \mathrm{mIU} / \mathrm{l}, 65,5 \%$ for TSH between 3.0 and $3.50 \mathrm{mIU} / \mathrm{l}, 87.5 \%$ for TSH between 3.5 and $4.0 \mathrm{mIU} / \mathrm{l}$, and $88.2 \%$ for TSH between 4 and 5 mIU/l (Figure 1).
Table 3: Cross tabulation for the categorized results according to free thyroid hormones and the TSH criteria. The figures in the table correspond to the percentage of cases from the total that fall within a specific category

\begin{tabular}{|c|c|c|c|c|c|}
\hline & \multirow[b]{2}{*}{ b TSH } & & \multicolumn{3}{|c|}{ Thyroid Hormones } \\
\hline & & & low & normal & elevated \\
\hline \multirow[t]{6}{*}{ TSH Innsbruck } & $<0.3$ & $\mathrm{n}$ & 8 & 71 & 19 \\
\hline & & $\%$ total & 0,31 & 2,76 & 0,74 \\
\hline & $0.3-3.5$ & $\mathrm{n}$ & 257 & 2056 & 39 \\
\hline & & $\%$ total & 10 & 80 & 1,52 \\
\hline & $>3.5$ & $\mathrm{n}$ & 19 & 100 & I \\
\hline & & $\%$ total & 0,74 & 3,89 & 0,04 \\
\hline \multirow[t]{6}{*}{ TSH Zöphel } & $<0.3$ & $\mathrm{n}$ & 8 & 71 & 19 \\
\hline & & $\%$ total & 0,31 & 2,76 & 0,74 \\
\hline & $0.3-3.35$ & $\mathrm{n}$ & 253 & 2039 & 38 \\
\hline & & $\%$ total & 9,84 & 79,34 & 1,48 \\
\hline & $>3.35$ & $\mathrm{n}$ & 23 & 117 & 2 \\
\hline & & $\%$ total & 0,89 & 4,55 & 0,08 \\
\hline \multirow[t]{7}{*}{ TSHBaloch } & $<0.3$ & $n$ & 8 & 71 & 19 \\
\hline & & $\%$ total & 0,31 & 2,76 & 0,74 \\
\hline & $0.3-2.5$ & $\mathrm{n}$ & 231 & 1888 & 34 \\
\hline & & $\%$ total & 8,99 & 73,46 & 1,32 \\
\hline & $>2.5$ & $\mathrm{n}$ & 45 & 268 & 6 \\
\hline & & $\%$ total & $\mathrm{I}, 75$ & 10,43 & 0,23 \\
\hline & s TSH & & low & normal & elevated \\
\hline \multirow{6}{*}{$\begin{array}{c}\text { Groups according } \\
\text { to stimulated TSH } \\
\text { values }\end{array}$} & $<2,5$ & $\mathrm{n}$ & 7 & 60 & 19 \\
\hline & & $\%$ total & 0,27 & 2,33 & 0,74 \\
\hline & $<19,9$ & $\mathrm{n}$ & 224 & 1857 & 36 \\
\hline & & $\%$ total & 8,72 & 72,26 & $\mathrm{I}, 4$ \\
\hline & $>=20$ & $n$ & 53 & 310 & 4 \\
\hline & & $\%$ total & 2,06 & 12,06 & 0,16 \\
\hline
\end{tabular}

\section{Discussion}

The environment of this study reflects a common situation encountered in modern medicine, i.e. a reference laboratory will only have a blood sample for the biochemical evaluation of the patient. For this reason, the clinical validity of any test has to be evaluated in relation to the physiology of the system being investigated. In the case of thyroid physiology, the TRH test provides a physiological insight of the metabolic state [22]. For this reason we used

Table 2: Categorized results according to 4 classification criteria for normal: I) basal TSH according to Innsbruck criteria (I-TSH), 2) TRH stimulated TSH levels (s-TSH), 3) basal TSH according to Zöphel (Z-TSH), 4) basal TSH according to Baloch (B-TSH). The figures in the table correspond to the percentage of cases from the total that fall within a specific category.

\begin{tabular}{cccccccc}
\hline I-TSH & $\%$ & s-TSH & $\%$ & Z-TSH & $\%$ & B-TSH & $\%$ \\
\hline$<0.3$ & 3,81 & $<2,5$ & 3,35 & $<0.3$ & 3,81 & $<0.3$ & 3,81 \\
$0.3-3.5$ & 91,52 & $<19,9$ & 82,37 & $0.3-3.35$ & 90,66 & $0.3-2.5$ & 83,77 \\
$>3.5$ & 4,67 & $>=20$ & 14,28 & $>3.35$ & 5,53 & $>2.5$ & 12,41
\end{tabular}


A: Definition of nomal response $=\mathrm{TSH}$ after TRH $20 \mathrm{mIE} / \mathrm{L}$

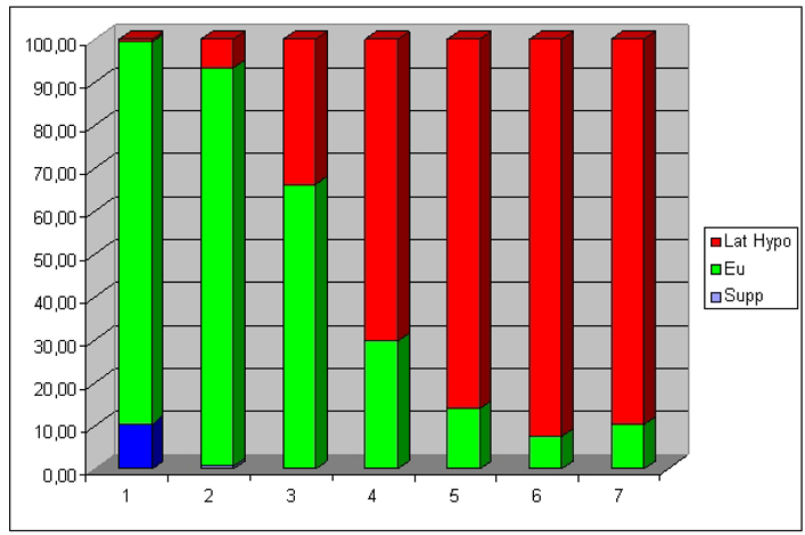

\section{Figure I}

The diagram shows the response of TSH to TRH stimulation. The $\mathrm{x}$-axis shows increasing TSH levels. The $\mathrm{Y}$-axis shows that proportion of patients having a suppressed TSH response (blue), a normal response (green) or an exagerated response (red), i.e. latent hypothyroidism.

the information provided by the TRH stimulation test for the evaluation of basal TSH levels in relation to the identification of latent and/or overt hypothyroidism. The normal range for TSH after TRH stimulation allowed us a similar categorical classification of patients as done with the values of free $\mathrm{TH}$, thus underscoring the physiological meaning of the TRH test. On the other hand, due to the use of sensitive TSH assays, the identification of hyperthyroidism does not represent a problem, although in some cases the determination of TSH alone can be deceiving [27].

Recently, the proposition put forth by Baloch et al. [26] to define the reference levels of TSH based on a preselected (biased ?) population of healthy subjects has been investigated by Zöphel et al. [19]. In spite of adhering to Baloch's theoretical postulate, they were not able to find a difference in the reference levels for TSH using a preselected or an unselected population [19]. Their result shows, that pre-selection of normals based on thyroid antibody titers and other parameters is not a requisite for the definition of TSH levels. These conclusions apply to our study. Interestingly the normal range defined by Zöphel shows a good correlation with our results, those of Baloch do not.

Several lines of evidence have appeared recently relating altered body function in the presence of sub clinical hypothyroidism making it relevant to be able to identify such patients [28-32]. Since our study was purely diagnostic, we can not compare our results to approaches that try to analyze the cost-effectiveness of treating latent hypothyroidism. On the other hand, the original setting of this evaluation was predominantly related to problems related to fertility, i.e. the field of reproductive endocrinology. Using a similar approach as ours, Raber et al. have been able to show that infertility can be positively influenced by thyroid hormone supplementation when latent hypothyroidism is present [24]. Poppe et al. have recently reviewed the relation between thyroid disease and reproductive function in females. They have pointed out that several strategies are used for the definition of the upper level for TSH in order to detect subclinical hypothyroidism [25]. In their analysis, they suggest that data taken from TRH-stimulation tests appear to be more sensitive than other methods for defining normal TSH levels [25]. This situation is of outmost importance for pregnancy outcome [33]. The use of risk population definitions based on the presence of thyroid antibodies will miss a significant number of women presenting overt/subclinical hypothyroidism during early pregnancy [34]. Positive thyroid antibodies in pregnant women might be a reflection of a Se deficiency state which requires supplementation in order to prevent thyroid disease [35]. In our experience Se supplementation can also be beneficial in cases of incipient thyroid disease [36] leading to a normalization of both thyroid function parameters as well as of thyroid function.

\section{Conclusion}

Our data analysis strategy supports a normal reference range for TSH of 0.3 to $3.5 \mathrm{mIU} / \mathrm{l}$. Either a clinical and laboratory control or a TRH test can be recommended for patients with basal TSH values lying between 3.0 and 3.5 $\mathrm{mIU} / \mathrm{l}$ in order to rule out latent hypothyroidism.

\section{Abbreviations}

TSH: thyroid stimulating hormone

\section{Competing interests}

The author(s) declare that they have no competing interests.

\section{Authors' contributions}

OD and HE carried out the clinical work with the patients. RM created the data based and carried out the statistical analyses.

\section{Acknowledgements}

The laboratory of the Department of Nuclear Medicine, Medical University Innsbruck, carried out the determinations of thyroid function parameters.

\section{References}

I. Gharib H, Tuttle RM, Baskin HJ, Fish LH, Singer PA, McDermott MT: Subclinical thyroid dysfunction: a joint statement on management from the American Association of Clinical Endocrinologists, the American Thyroid Association, and the Endocrine Society. J Clin Endocrinol Metab 2005, 90:58I-585. 
2. Ringel MD, Mazzaferri EL: Subclinical thyroid dysfunction--can there be a consensus about the consensus? J Clin Endocrinol Metab 2005, 90:588-590.

3. Wartofsky L, Dickey RA: The evidence for a narrower thyrotropin reference range is compelling. J Clin Endocrinol Metab 2005, 90:5483-5488.

4. Surks MI, Goswami G, Daniels GH: The thyrotropin reference range should remain unchanged. J Clin Endocrinol Metab 2005, 90:5489-5496

5. Brabant G, Beck-Peccoz P, Jarzab B, Laurberg P, Orgiazzi J, Szabolcs I, Weetman AP, Wiersinga WM: Is there a need to redefine the upper normal limit of TSH? Eur J Endocrinol 2006, 154:633-637.

6. De Rosa G, Testa A, Giacomini D, Carrozza C, Maussier ML, Valenza V, D'Errico GF: Comparison between TRH-stimulated TSH and basal TSH measurement by a commercial immunoradiometric assay in the management of thyroid disease. $Q J \mathrm{NuCl}$ Med 1996, 40: 182-187.

7. Taimela E, Kairisto V, Koskinen P, Leino A, Irjala K: Reference intervals for serum thyrotropin, free thyroxine and free triiodothyronine in healthy adults in Finland, measured by an immunoautomate based on time-resolved fluorescence (AutoDELFIA). Eur J Clin Chem Clin Biochem 1997, 35:889-890.

8. Bjoro T, Holmen J, Krüger O, Midthjell K, Hunstad K, Schreiner T, Sandnes L, Brochmann H: Prevalence of thyroid disease, thyroid dysfunction and thyroid peroxidase antibodies in a large, unselected population. The Health Study of Nord-Trondelag (HUNT). Eur J Endocrinol 2000, I 43:639-647.

9. Steinmetz J, Spyckerelle Y, De Talance N, Fournier B, Boulange M, Leclere J, Giordanella JP: Factors of variation and reference values for TSH in 45-70 year old women. Ann Endocrinol (Paris) 2000, 6 I:50I-507.

10. Hollowell JG, Staehling NW, Flanders WD, Hannon WH, Gunter EW, Spencer CA, Braverman LE: Serum TSH, T(4), and thyroid antibodies in the United States population (1988 to 1994): National Health and Nutrition Examination Survey (NHANES III). J Clin Endocrinol Metab 2002, 87:489-499.

II. Hubl W, Schmieder J, Gladrow E, Demant T: Reference intervals for thyroid hormones on the architect analyser. Clin Chem Lab Med 2002, 40:165-166.

12. Hübner U, Englisch C, Werkmann H, Butz H, Georgs T, Zabransky S Herrmann W: Continuous age-dependent reference ranges for thyroid hormones in neonates, infants, children and adolescents established using the ADVIA Centaur Analyzer. Clin Chem Lab Med 2002, 40:1040-1047.

13. Gonzalez-Sagrado M, Martin-Gil FJ: Population-specific reference values for thyroid hormones on the Abbott ARCHITECT i2000 analyzer. Clin Chem Lab Med 2004, 42:540-542.

14. Jensen E, Hyltoft PP, Blaabjerg O, Hansen PS, Brix TH, Kyvik KO, Hegedüs L: Establishment of a serum thyroid stimulating hormone (TSH) reference interval in healthy adults. The importance of environmental factors, including thyroid antibodies. Clin Chem Lab Med 2004, 42:824-832.

15. d'Herbomez M, Jarrige $V$, Darte C: Reference intervals for serum thyrotropin (TSH) and free thyroxine (FT4) in adults using the Access Immunoassay System. Clin Chem Lab Med 2005, 43:102- 105.

16. Kratzsch J, Fiedler GM, Leichtle A, Brugel M, Buchbinder S, Otto L, Sabri O, Matthes G, Thiery J: New reference intervals for thyrotropin and thyroid hormones based on National Academy of Clinical Biochemistry criteria and regular ultrasonography of the thyroid. Clin Chem 2005, 5 I: | 480-1486.

17. Moncayo R, Moncayo H, Virgolini I: Reference values for thyrotropin. Thyroid 2005, I5:1204-1205.

18. Völzke H, Alte D, Kohlmann T, Lüdemann J, Nauck M, John U, Meng W: Reference intervals of serum thyroid function tests in a previously iodine-deficient area. Thyroid 2005, 15:279-285.

19. Zöphel K, Wunderlich G, Gruning T, Koch R, Doge H, Kotzerke J: [Where does subclinical hypothyroidism start? Implications for the definition of the upper reference limit for thyroid stimulating hormone]. Nuklearmedizin 2005, 44:56-6I.

20. Dhatt GS, Griffin G, Agarwal MM: Thyroid hormone reference intervals in an ambulatory Arab population on the Abbott Architect i2000 immunoassay analyzer. Clin Chim Acta 2006, 364:226-229.

21. O'Leary PC, Feddema PH, Michelangeli VP, Leedman PJ, Chew GT, Knuiman M, Kaye J, Walsh JP: Investigations of thyroid hor- mones and antibodies based on a community health survey: the Busselton thyroid study. Clin Endocrinol (Oxf) 2006, 64:97-104.

22. Faglia G: The clinical impact of the thyrotropin-releasing hormone test. Thyroid 1998, 8:903-908

23. Vierhapper $\mathrm{H}$ : [Assessment of thyroid gland function in unwanted infertility-- indications for TRH test and clinical impact from the viewpoint of the endocrinologist]. Acta Med Austriaca 1997, 24:133-135.

24. Raber W, Nowotny P, Vytiska-Binstorfer E, Vierhapper H: Thyroxine treatment modified in infertile women according to thyroxine-releasing hormone testing: 5 year follow-up of 283 women referred after exclusion of absolute causes of infertility. Hum Reprod 2003, 18:707-7|4.

25. Poppe K, Velkeniers B, Glinoer D: Thyroid disease and female reproduction. Clin Endocrinol (Oxf) 2007, 66:309-32I.

26. Baloch Z, Carayon P, Conte-Devolx B, Demers LM, Feldt-Rasmussen U, Henry JF, LiVosli VA, Niccoli-Sire P, John R, Ruf J, Smyth PP, Spencer CA, Stockigt JR: Laboratory medicine practice guidelines. Laboratory support for the diagnosis and monitoring of thyroid disease. Thyroid 2003, 13:3-126.

27. Dayan CM: Interpretation of thyroid function tests. Lancet 200I, 357:619-624

28. Constant EL, De Volder AG, Ivanoiu A, Bol A, Labar D, Seghers A, Cosnard G, Melin J, Daumerie C: Cerebral blood flow and glucose metabolism in hypothyroidism: a positron emission tomography study. J Clin Endocrinol Metab 200I, 86:3864-3870.

29. Krausz Y, Freedman N, Lester H, Newman JP, Barkai G, Bocher M, Chisin $\mathrm{R}$, Bonne $\mathrm{O}$ : Regional cerebral blood flow in patients with mild hypothyroidism. J Nucl Med 2004, 45: 17/2-17/5.

30. Owen PJ, Rajiv C, Vinereanu D, Mathew T, Fraser AG, Lazarus JH: Subclinical hypothyroidism, arterial stiffness, and myocardial reserve. J Clin Endocrinol Metab 2006, 91:2 I26-2I 32.

31. Rodondi N, Aujesky D, Vittinghoff E, Cornuz J, Bauer DC: Subclinical hypothyroidism and the risk of coronary heart disease: a meta-analysis. Am J Med 2006, I I 9:54I-55I.

32. Chueire VB, Romaldini JH, Ward LS: Subclinical hypothyroidism increases the risk for depression in the elderly. Arch Gerontol Geriatr 2007, 44:2I-28.

33. Idris I, Srinivasan R, Simm A, Page RC: Maternal hypothyroidism in early and late gestation: effects on neonatal and obstetric outcome. Clin Endocrinol (Oxf) 2005, 63:560-565.

34. Vaidya B, Anthony S, Bilous M, Shields B, Drury J, Hutchison S, Bilous $R$ : Detection of thyroid dysfunction in early pregnancy: Universal screening or targeted high-risk case finding? J Clin Endocrinol Metab 2007, 92:203-207.

35. Negro R, Greco G, Mangieri T, Pezzarossa A, Dazzi D, Hassan H: The Influence of Selenium Supplementation on Postpartum Thyroid Status in Pregnant Women with Thyroid Peroxidase Autoantibodies. J Clin Endocrinol Metab 2007, 92: 1263-I 268.

36. Moncayo R, Moncayo H, Kapelari K: Nutritional treatment of incipient thyroid autoimmune disease. Influence of selenium supplementation on thyroid function and morphology in children and young adults. Clin Nutr 2005, 24:530-53I.

\section{Pre-publication history}

The pre-publication history for this paper can be accessed here:

http://www.biomedcentral.com/1472-6823/7/5/prepub 